\title{
Subtle Psychosocial Sequelae of Genetic Test Results
}

\author{
Robin E. Grubs • Lisa S. Parker • Rebekah Hamilton
}

Published online: 20 August 2014

(c) Springer Science + Business Media New York 2014

\begin{abstract}
Research using standard psychological measures has not revealed a dramatic psychological reaction to receipt of predictive genetic test results. Qualitative research, however, indicates that there are subtle psychosocial sequelae of receiving such results that should be considered by individuals and their clinicians prior to testing. Among these more subtle, but burdensome sequelae of testing are (i) changed social relationships (including relationships with clinicians), (ii) the impact of test results on important life decisions (e.g., career and reproductive choices), and (iii) altered self-concept among those tested. This review examines these more subtle sequelae, as well as the inadequacy of existing quantitative measures for assessing their impact, and discusses the relevance of such sequelae for decision-making about predictive genetic testing.
\end{abstract}

Keywords Genetic testing - Predictive testing ·

Psychosocial concerns · Ethics - Qualitative research .

BRCA · Huntington disease

\section{Introduction}

Early enthusiasm about the possibility of using genetic information to analyze disease risk in asymptomatic individuals to prevent disease and reduce morbidity and

R. E. Grubs $(\bowtie) \cdot$ L. S. Parker

Department of Human Genetics, The University of Pittsburgh, A300 Crabtree Hall, 130 DeSoto St, Pittsburgh, PA 15261, USA e-mail: rgrubs@pitt.edu

R. Hamilton

College of Nursing, Rush University, 600 S. Paulina St, Chicago,

IL 60612, USA mortality was accompanied by concern about potential psychosocial burdens associated with learning one's genetically related risk of disease. There is now substantial experience with predictive genetic testing for a range of conditions including hereditary breast and ovarian cancer (HBOC), some forms of inherited colorectal cancer, long QT syndrome, and some neurological conditions [1-7].

Early experience studying psychosocial sequelae, particularly within the Huntington disease community, both reveals some unexpected responses to test results and indicates that negative sequelae are not as severe as initially feared [1, 2, 8-12]. Nevertheless, early experience also indicates that there are more subtle sequelae to which clinicians and individuals considering genetic testing should attend and that the scaled instruments developed to measure psychosocial distress in other contexts are not well suited to assess sequelae of genetic testing/risk analysis. Among these more subtle, but nevertheless burdensome outcomes of testing are (i) changed social relationships (including relationships with clinicians), (ii) the impact of test results on important non-medical life decisions, and (iii) altered self-concept of those tested. Drawing primarily from qualitative research on HBOC genetic testing, this review examines these more subtle sequelae, as well as the inadequacy of existing quantitative measures for assessing their impact, and discusses the relevance of such sequelae for decision-making about genetic testing.

\section{Early Concerns and Assessment of Sequelae}

Although families of individuals affected with Huntington disease (HD) strongly supported development of a predictive genetic test, medical geneticists, and bioethicists expressed concern that increased rates of depression, 
anxiety, suicidality, and suicide would be associated with receipt of a positive test result. Elaborate pre- and post-test evaluation and counseling protocols were developed to ensure that individuals seeking testing were competent and made an informed decision to be tested and receive their test results, to reduce the risk that individuals testing positive for the gene would become severely depressed and specifically to detect suicidality [13-16]. Two outcomes surprised the genetics community when HD genetic testing was implemented as the first predictive testing program. First, there was substantially less uptake of testing than interest in the search for the gene had suggested (only $2-16 \%$ actually took the test, compared to the $57-84 \%$ of at-risk individuals who had previously expressed interest) [17-28]. Second, some who received a negative result expressed regret about opportunities forgone, while they lived in the shadow of a $50 \%$ chance of developing HD or expressed something akin to "survivor guilt" that they were spared from having the gene mutation that affected their loved ones [8-11]. At the same time, the feared high incidence of suicide and suicidality did not emerge following introduction of HD predictive testing, and those who undergo genetic testing for HD do not experience long term distress $[1,2,12]$.

To assess the psychological impact of HD predictive testing, researchers employed a variety of psychometric instruments to measure emotional states such as anxiety, distress, and depression [1-3]. This empirical approach to measuring psychological impact of genetic testing has continued as other predictive tests have entered the clinical arena (e.g., BRCA 1/2 testing). In general, we have learned from this work that individuals who elect predictive genetic testing do not exhibit serious psychopathological responses after testing $[1-3,29,30]$. By measuring psychological variables before and at one or more time points after testing, it has been shown in a number of studies that those without the risk-conferring mutation exhibit a decrease or no change in emotions such as anxiety, distress, and depression over time after receiving their test result. Those with the mutation have shown either no difference or a decrease in such emotions [1-3, 29-31].

Several studies tried to identify predictors of adverse psychological outcomes after testing in order to identify individuals who would benefit from additional counseling support [14, 32]. Not surprisingly, baseline levels of a particular attribute tend to predict the post-test measurement of the attribute, and higher levels of pretest distress have been found to predict poorer post-test adjustment. For example, in a HD predictive genetic testing study, individuals who experienced intrusive feelings and thoughts about HD and tried to avoid focusing on HD before testing were more likely to continue avoidance behavior after receiving their test results [33]. Similarly, the presence of baseline cancer-related stress symptoms was predictive of depression at follow-up evaluations in individuals who were offered but declined BRCA $1 / 2$ genetic testing [34].

The use of standard instruments to measure the impact of predictive testing identified particular groups of individuals who may be at risk for an adverse outcome in a few studies, but the majority of research in this area demonstrated that the most at-risk individuals who elect for predictive testing adapt well to their test results and do not experience serious psychopathological consequences $[1-3$, 29-31]. Recognizing that standard psychological measures provide only a particular perspective on life after genetic testing, some investigators have used other methods to examine the emotional and psychosocial aspects of living with genetic risk. Their research reveals that knowing one carries a risk-conferring mutation affects individuals in different and more subtle ways.

\section{Assessing Subtle Sequelae of Genetic Testing}

As has been witnessed among those living with chronic illness [35-37], living with chronic risk of disease after receiving a positive genetic test result has been shown to have psychosocial effects. Qualitative research involving interviews or focus groups can reveal psychosocial impacts not reflected in quantitative measures. These relatively, subtle, everyday considerations group around three themes: changed social relationships, impact on life decisions, and altered self-concept. That these effects segregate around themes suggest that although the prevalence of these experiences has not yet been established, the experiences are sufficiently common (both in frequency and in being shared) that individuals would be well served to consider such potential sequelae prior to undergoing testing. Further, clinicians should be prepared to discuss such potential outcomes with their patients/clients.

\section{Changed Social Relationships}

\section{With Family Members}

An emerging body of research describes changes in social relations after genetic testing. Metcalfe et al. [38] found that in approximately, half of their sample of women with a BRCA mutation, familial, and personal relations were negatively impacted. Participants described their preoccupation with their genetic status as reducing their emotional availability to husbands and children. A thematic analysis study by Douglas et al. [39] examined the impact of BRCA testing on family relationships and found that participants who were the first family member to be tested felt an obligation to disclose their BRCA mutation to other family 
members and sometimes perceived this obligation to be a burden. In addition, while some participants reported that testing enhanced a sense of family cohesiveness because they felt more connected to their family members with whom they shared a mutation, others reported feeling disconnected and socially isolated within their family.

Among participants in their focus group study with women under age 40 who were diagnosed with breast cancer and who carry a BRCA1/2 mutation, Kenen et al. [40] identified a sense of social separation: "an emotional estrangement - an emotional distance or pulling away from or dissonance with the groups that individuals interact with or are part of, e.g. family, friends" (p. 151). Moreover, although each participant had at least one completely supportive loved one, this support often proved insufficient to counteract the feelings of being alone.

In studies asking young women (age 18-39) to describe their experiences of genetic testing for BRCA mutations and the decisions they faced after testing positive for a mutation, Hamilton found that these women typically speak of the impact on family relations, fears felt for themselves and other family members, estrangement from peers, and an overall new sense of vulnerability based on the knowledge of carrying a gene mutation $[8,41]$. Excerpts from two in-depth interviews describe changes in the women's family relationships and self-perceptions [8, 41]:

I also remember having to enter my in-laws' household...I remember avoiding them when we came into the house and waiting upstairs while my husband told them the bad news [i.e., having a BRCA1 mutation]. I felt like damaged goods. Somehow, as if they would think my husband had made a mistake marrying methat I was such a liability to him or to them.

I was very sensitive about how the results might make others see me. For instance, I was concerned that my husband [then boyfriend's] family and friends would try to talk him out of being with me [citing reasons like polluting his genes, being too much work, etc.]. Especially after my husband proposed, I was concerned that his friends and family would think that he was marrying me out of pity.

\section{With Friends}

Another study found that higher levels of personal and social support were positively associated with higher levels of selfesteem and lower levels of personal distress in women at risk for HBOC [42]. Friendships are an important source of social support, and most of these typically occur within one's peer group. Yet living with increased risk of disease involves not only knowledge but also actions-such as increased surveillance or preventive interventions - that put young women out of synch with their peers [40, 41]. Women with BRCA1/2 mutations may choose to have prophylactic mastectomy, which sets them apart from their peers. One 34-year old who had a prophylactic mastectomy described a shopping spree with friends where she felt distinctly different [43]:

You know people are trying on things...and my friends are like 'oh that looks so cute'...'I don't have the boobs to fill that out' and comments like that, and then there was this big huge thing everyone was talking about who has boobs and who doesn't and whose are small and whose are big, and I am thinking how stupid can these people be and they are my friends (laugh) and of course, that is not what they are thinking about at the time.

At a time, when their friends are focused on more seemingly frivolous activities and on education and careers, young BRCA+ women face questions of mortality, make important health-related decisions, and express a sense of urgency to make key decisions about marriage and child bearing, while friends may be more involved with education and careers [44, 45].

\section{With Clinicians or the Healthcare System}

Most of the literature on the impact of knowing one's genetic risk on the patient-provider relationship addresses informed consent [46], provider perspectives on disclosing genetic test results to family members [47, 48], and testing adolescents for adult-onset diseases [49, 50]. Werner-Lin reported that while genetic counselors and physicians provide formal informational support, these providers did not provide the emotional support to women often needed following a positive genetic test [51]. Some women interviewed report a change in the number and nature of encounters with healthcare providers, leading those tested to have a sense of a changed life after genetic testing [52]. One young woman reports

My ovary surveillance has been set up as CA-125 tests every three months, ultrasounds and pelvic exams by my gynecology oncologist every six months. My screening and testing permeate my life. Emotionally it sucks...since my genetic test result "normal life" has changed to having to always have an underlying BRCA vibe.

Hamilton found that some young women report troubling encounters with mammogram technicians who questioned why they were there, complained they were "wasting valuable resources," or required the young women to provide lengthy justifications for why they were 
there in the first place, instead of providing support during the emotionally difficult experience of having mammography while living with increased breast cancer risk.

Impact on Life Decisions

\section{Career Choice}

Little has been reported on the impact on career choices of knowing one is at an increased risk for an adult-onset disorder. Qualitative data suggest that some people change what they planned to do [44]. Hamilton observed that younger women frequently view life as involving making a plan and carrying it out. Being BRCA+ may lead young women to question, alter, or speed up their plans, for example:

I was kind of putting my future into blocks of time and saying, "Okay, I'll finish my undergrad degree here. I wanted to go to law school. I thought I'll have three years there and then it'll be marriage and kids and then surgeries," and it was just I felt like there was so much pressure to just have this plan...

Instead of following through with those plans, she left a five-year relationship and took a fellowship with a nonprofit organization in East Asia, observing:

... everything in my body is telling me I need to go and try this out...Thinking about my genetic status, it has been a fairly large factor in that decision and just thinking about what that means for leaving, but at the end of the day it's still the right choice, I believe.

The impact on career plans is not always so positive, however. Prior to, and even despite the 2008 passage of the Genetic Information Nondiscrimination Act, concern about discrimination on the basis of genetic risk shapes careerrelated decisions. As one woman shared with Hamilton,

I...was laid off about a year after my diagnosis...My dad was really just concerned about all three of us and whether we would be discriminated against in the work force if something were to come up because of this gene. I was lucky enough to go back to a company that I used to work for so they knew about my diagnosis and the mutation, so it's not been a problem.

Identification of a risk-conferring mutation may quite reasonably incline people toward careers and employers with good health benefits and health insurance plans, and away from other careers or self-employment. Hamilton found that even women who are positively influenced by their mutation status to choose rewarding BRCA-related careers, subsequently find that their BRCA status complicates their work and the separation of their work and professional life.

I am a breast care navigator as a nurse, and so all I do is see breast cancer...I sorta feel anxious about this, and sorta feel like I'm a ticking time bomb. I think because I've gotten older... and I'm surrounded by it. So, actually like my state of mind mentally has changed drastically.

\section{Dating, Mating, and Family Planning Decisions}

For younger women, their knowledge of their increased risk for HBOC can engender a sense of urgency to find a partner and have children [44, 45]. Based on her interviews, Werner-Lin [44] notes, "the experience of creating a life plan that integrates the possibility of early illness and death is out of synch with normative developmental tasks of establishing intimate relationships and the start of family planning" (p. 427). Unmarried/unpartnered participants in her study were anxious to find partners within a relatively short time and start a family before being diagnosed with cancer or having prophylactic surgery that would eliminate the possibility of having a biological child. Participants also spoke of feeling "damaged" and of how their search for a partner was complicated by fears that a potential mate would not be interested in forming a relationship with someone who might face a life threatening illness or whose physical appearance and sexuality would be altered by prophylactic surgeries.

Hamilton identified similar concerns in her interviews with young, single women [41].

There was a guy that I started to become really good friends with this past semester...it didn't go anywhere but...gave me so much anxiety just even in the beginning of friendship because I had no idea where it would go or anything...so it just weighed on me constantly to where I just had to tell him... cause my whole thing was like oh my gosh these [breasts] aren't mine and just having to tell him that, and [I] also wanted to make sure that they understand that because I don't want anybody to think oh my gosh she might die soon and so why start a relationship with her...

In qualitative interviews with individuals at risk or symptomatic for HD, alpha-1 antitrypsin deficiency, and HBOC, Klitzman and Sweeney [53] also found that participants faced difficult decisions regarding whether to disclose genetic information and if so, when, how, and what type of information to share, particularly with a potential partner. Some chose not to date to avoid the challenges inherent in disclosing such emotionally charged 
information. Others avoided disclosure or disclosed information in an "indirect and inadvertent" manner-for example, a partner unexpectedly meeting affected family members-due to personal experience with, or concern about, rejection.

\section{Impact on Self-Concept}

Learning genetic information affects individuals' understanding of themselves both directly and through changes in their interpersonal interactions and relationships. Selfconcept or one's "sense of self is an inner and private phenomenon, unique to an individual, unknowable directly to others," which is formed by reflecting on oneself and others' reactions to oneself [54]. An individual typically constructs a self-identity in light of characteristics and circumstances deemed particularly important—even essential - to that individual in her own and others' eyes: athlete, the good daughter, the high-powered businessperson.

Recognizing the potential psychosocial impact of genetic test results, in the first decade of the 21st Century, commentators suggested the "new genetics" would create a new population, "the worried well," asymptomatic individuals who conceived of themselves as pre-diseased $[55,56]$. There is now evidence that individuals who learn of their genetic risk for disease do alter their self-concept or form new self-identities.

In an ethnographic study, the three youngest participants who had received a positive mutation test result described thinking about their risk every day and having both their present and future self-concept affected [57]. Another subset described themselves as not ill but as no longer seeing themselves as healthy either. Friedman terms this new identity, identified among research participants with BRCA1/2 mutations, as the "previvor," one who identifies as a pre-cancer-survivor, who lives with increased risk but who has not had cancer [58]. Young BRCA + women describe themselves as "damaged goods" and as a walking "time bomb" [43].

Beginning a career, forming romantic relationships, and becoming a parent have long been considered important milestones that signify a transition into young adulthood [59-64]. Evidence reviewed here suggests that it may be important to carefully time decisions about predictive genetic testing and receipt of genetic information to minimize disruption of the formation of adult self-concept, life plans, and the social relationships that are integral to both. Analyzing her findings, D'Agincourt-Canning [57] specifically raises for further inquiry the question: "Does age or life stage affect how genetic information is interpreted and used?" (p. 469).
In his qualitative study exploring issues of identity in individuals who had or were at risk for $\mathrm{HD}, \mathrm{HBOC}$, or alpha1 antitrypsin deficiency, Klitzman [65] described challenges they faced when trying to integrate genetic information into their senses of self. Facing uncertainties and ambiguities when trying to understand genetic information-particularly when confronting the complexities of prognosis, penetrance, and predisposition-these individuals look to "socially established categories" such as "sick," "diseased," "healthy," and "disabled" to make sense of their experiences. Klitzman noted that stigma associated with having a mutation can complicate the process of incorporating genetic information into one's self-concept, and that when having a mutation was perceived negatively, individuals sometimes described themselves as "mutants" and "freaks of nature." Klitzman concludes that "it is vital that health care providers be aware of the multifacetedness and vagaries of these issues - of the fluid, protean nature of identity, and patients' struggles to establish satisfactory senses of self, and the ways these phenomena can affect patients' health decisions" (p. 888).

\section{Relevance of these Subtle Sequelae for Informed Consent and Pre-test Counseling}

Obtaining the informed voluntary consent of a competent patient is an ethical and legal prerequisite for performing an invasive medical intervention, and disclosure of information relevant to patients' decision-making is a necessary condition for informed consent [66]. Obtaining informed consent for genetic testing has generally been standard practice, not because before the introduction of noninvasive genetic testing (e.g., cheek swabs), genetic testing involved at least a blood draw, but because of the significance of the information to be obtained. Genetic information's significance, including its implications for family members, led to informed consent and pre-test counseling not typical of other diagnostic testing and preventive medical assessments.

The elaborate pre-test protocols for HD genetic testing, whose results are still not clinically actionable, though they may have personal value for life planning, were partly motivated by the perceived need to identify individuals at risk for having pathological responses to test results. Experience has allayed those concerns [1, 2, 12-14, 16]. Informed consent and pre-test counseling in other contexts where the results are "clinically actionable" are grounded in recognition that if genetic risk information is to be beneficial, further action should be subsequently undertaken by those tested, e.g., lifestyle changes, prophylactic surgeries, or other interventions. "Clinical actionability" of 
genetic test results comprises actions that require the active participation of those tested.

Given experience suggesting that some of those tested experience nonpathological but burdensome psychosocial sequelae of learning genetic risk information, informing those considering genetic testing about the range of these more subtle, "everyday" responses may enable them to make a more informed and better timed decision about testing. Qualitative research suggests that some of those tested would have found knowledge of the nature and intensity of these subtle sequelae relevant to their decisions to seek testing [38-41, 43-45]. Supplying information material to patients' decision making is ethically and legally required in the disclosure phase of informed consent. Moreover, with increased awareness of these possible sequelae, clinicians can offer supportive post-testing interventions and referrals. Instead of watching only for signs of depression, suicide, or severe maladjustment, clinicians can inquire about the everyday impact of learning genetic risk information and respond more supportively.

\section{Implications for Managing Incidental Findings}

The studies reviewed to elucidate these nonpathological, subtle, yet frequently life-changing psychosocial sequelae of learning genetic information focused on the responses of individuals who specifically sought genetic testing, often because of family experience with the gene-associated condition. In recent years, there is growing interest in (and debate about) disclosing to patients the incidental findings of clinical genetic testing or sequencing [67-70]. It would be reasonable to suspect that receipt of such genetic risk information that is neither sought nor anticipated might be even more disruptive of social relationships, life plans, and self-concept. Research is needed to determine whether such sequelae result, and their nature, magnitude, and prevalence. Though there is reason to believe that individuals adapt emotionally and psychologically in effective nonpathological ways to genetic test results in the presence of informed consent and genetic counseling, additional research should focus on the more subtle impacts described here, and on whether results generated without specific informed consent and disclosed in primary care settings by those without training in genetic counseling may exacerbate these sequelae or complicate adaptation. These considerations-and continued research tracking patient responses-are especially important in light of recommendations from the American College of Medical Genetics [71, 72] regarding disclosure of incidental findings of genomic sequencing that, if followed, would expand the number of individuals receiving genetic information regarding their disease risks without specifically seeking such information and outside of genetics clinics. As this review demonstrates, the "everyday-ness" of the impact of such information means that the distress occasioned by such information is not discerned by standard instruments measuring psychological distress, yet it is the "everyday-ness" of the sequelae that constitutes their distressing nature.

Acknowledgments The authors would like to thank Lauren Brown and Alicia Martinez for their assistance in the preparation of the manuscript.

Disclosure RE Grubs, LS Parker, and R Hamilton all declare no conflicts of interest.

Human and Animal Rights and Informed Consent All studies by the authors involving animal and/or human subjects were performed after approval by the appropriate institutional review boards. When required, written informed consent was obtained from all participants.

\section{References}

1. Broadstock M, Michie S, Marteau T. Psychological consequences of predictive genetic testing: a systematic review. Eur J Hum Genet. 2000;8:731-8.

2. DudokdeWit AC, Duivenvoorden HJ, Passchier J, Niemeijer MF, Tibben A, and the other members of the Rotterdam/Leiden Genetics Workgroup. Course of distress experienced by persons at risk for an autosomal dominant inheritable disorder participating in a predictive testing program: an explorative study. Psychosom Med. 1998;60:543-9.

3. Evers-Kiebooms G, Welkenhuysen M, Claes E, Decruyenaere M, Denayer L. The psychological complexity of predictive testing for late onset neurogenetic diseases and hereditary cancers: implications for multidisciplinary counselling and for genetic education. Soc Sci Med. 2000;51:831-41.

4. Aatre RD, Day SM. Psychological issues in genetic testing for inherited cardiovascular diseases. Circ Cardiovasc Genet. 2011;4:81-90.

5. Hendriks KSWH, Hendriks MMWB, Birnie E, Grosfeld FJM, Wilde AAM, van den Bout J, Smets EMA, van Tintelen JP, ten Kroode HFJ, van Langen IM. Familial disease with a risk of sudden death: a longitudinal study of the psychological consequences of predictive testing for long QT syndrome. Heart Rhythm. 2008;5:719-24.

6. Modell SM, Bradley DJ, Lehmann MH. Genetic testing for long QT syndrome and the category of cardiac ion channelopathies. PLOS Curr Evid Genomic Tests. 2012;1:1-14.

7. Roberts JS, Uhlmann WR. Genetic susceptibility testing for neurodegenerative diseases: ethical and practice issues. Prog Neurobiol. 2013;110:89-101.

8. Hamilton RJ, Bowers BJ, Williams JK. Disclosing genetic test results to family members. J Nurs Scholarsh. 2005;37:18-24.

9. Sobel S, Cowan CB. Impact of genetic testing for Huntington disease on the family system. Am J Med Genet. 2000;90:49-59.

10. Williams JK, Schutte DL, Evers C, Holkup PA. Redefinition: coping with normal results from predictive genetic testing for neurodegenerative disorders. Res Nurs Health. 2000;23:260-9.

11. Huggins M, Bloch M, Wiggins S, Adam S, Suchowersky O, Trew $M$, et al. Predictive testing for Huntington disease in Canada: adverse effects and unexpected results in those receiving a decreased risk. Am J Med Genet A. 1992;42:508-15. 
12. Williams JK, Erwin C, Juhl A, Mills J, Brossman B, Paulsen JS. Personal factors associated with reported benefits of Huntington disease family history or genetic testing. Genet Test Mol Biomarkers. 2010;14:629-36.

13. Almqvist EW, Bloch M, Brinkman R, Craufurd D, Hayden MR. A worldwide assessment of the frequency of suicide, suicide attempts, or psychiatric hospitalization after predictive testing for Huntington disease. Am J Hum Genet. 1999;64:1293-304.

14. Almqvist EW, Brinkman RR, Wiggins S, Hayden MR. Psychological consequences and predictors of adverse events in the first 5 years after predictive testing for Huntington's disease. Clin Genet. 2003;64:300-9.

15. Nance M, Meyers R, Wexler A, Zanko A. US Huntington's Disease Genetic Testing Group. Genetic testing for huntington's disease: its relevance and implications (revised). USA: Huntington's Disease Society of America; 2003. Retrieved from http://www.hdsa.org/images/content/1/1/11884.pdf. Accessed 3 August 2014

16. Wahlin TB, Lundin A, Backman L, Almqvist EW, Haegermark A, Winblad B, Anvret M. Reactions to predictive testing in Huntington disease: case reports of coping with a new genetic status. Am J Med Genet. 1997;73:356-65.

17. Quaid KA, Morris M. Reluctance to undergo predictive testing: the case of Huntington disease. Am J Med Genet. 1993;45:41-5.

18. Bernhardt C, Schwan AM, Kraus P, Epplen JT, Kunstmann E. Decreasing uptake of predictive testing for Huntington's disease in a German centre: 12 years' experience (1993-2004). Eur J Hum Genet. 2009;17:295-300.

19. Tassicker RJ, Teltscher B, Trembath MK, Collins V, Sheffield L, Chiu E, Gurrin L, Delatycki MB. Problems assessing uptake of Huntington disease predictive testing and a proposed solution. Eur J Hum Genet. 2009; 17:66-70.

20. Trembath MK, Tassicker RJ, Collins VR, Mansie S, Sheffield LJ, Delatycki MB. Fifteen years of experience in predictive testing for Huntington disease at a single testing center in Victoria. Aust Genet Med. 2006;8:673-80.

21. Binedell J, Soldan JR. Nonparticipation in Huntington's disease predictive testing: reasons for caution in interpreting findings. J Genet Couns. 1997;6:419-32.

22. Evers-Kieboom G, Cassiman JJ, van de Berghe H. Attitudes towards predictive testing in Huntington's disease: a recent survey in Belgium. J Med Genet. 1987;24:275-9.

23. Kessler S, Field T, Worth L, Mosbarger H. Attitudes of persons at risk for Huntington disease toward predictive testing. Am J Med Genet. 1987;26:259-70.

24. Teltscher B, Polgar S. Objective knowledge about Huntington's disease and attitudes towards predictive testing of persons-at risk. J Med Genet. 1981;18:31-9.

25. Tyler A, Ball D, Craufurd D. Presymptomatic testing for Huntington's disease in the United Kingdom. The United Kingdom Huntington's disease prediction consortium. BMJ. 1992;304: 1593-6.

26. Bloch M, Fahy M, Fox S, Hayden MR. Predictive testing for Huntington's disease II: demographic characteristics, life style patterns, attitudes and psychosocial assessment of the first fiftyone test candidates. Am J Med Genet. 1989;32:217-24.

27. World Federation of Neurology Research Group on Huntington's. Disease. Presymptomatic testing for Huntington's disease: a worldwide survey. J Med Genet. 1993;30:1020-2.

28. Maat-Kievit A, Vegter-van der Vlis M, Zoeteweij M, Losekoot M, van Haeringen A, Roos R. Paradox of a better test for Huntington's disease. J Neurol Neurosurg Psychiatry. 2000;69:579-83.

29. Foster C, Watson M, Eccles D, Ashley S, Davidson R, Mackay J, Morrison PJ, Hopwood P, Evans DG. Predictive genetic testing for BRCA1/2 in a UK clinical cohort: three-year follow-up. Br J Cancer. 2007;96:718-24.
30. Butow PN, Lobb EA, Meiser B, Barratt A, Tucker KM. Psychological outcomes and risk perception after genetic testing and counselling in breast cancer: a systematic review. Med J Aust. 2003;178:77-81.

31. Smith AW, Dougall AL, Posluszny DA, Somers TJ, Rubinstein WS, Baum A. Psychological distress and quality of life associated with genetic testing for breast cancer risk. Psycho-oncology. 2008; 17:767-73.

32. Lawson K, Wiggins S, Green T, Adam S, Bloch M, Hayden MR, The Canadian Collaborative Study Predictive Testing. Adverse psychological events occurring in the first year after predictive testing for Huntington's disease. J Med Genet. 1996;33:856-62.

33. Tibben A, Duivenvoorden HJ, Vegter-van der Vlis M, Niermeijer MF, Frets PG, van de Kamp JJ, et al. Presymptomatic DNA testing for Huntington disease: identifying the need for psychological intervention. Am J Med Genet. 1993;48:137-44.

34. Lerman C, Hughes C, Lemon SJ, Main D, Snyder C, Durham C, et al. What you don't know can hurt you: adverse psychologic effects in members of BRCA1-linked and BRCA2-linked families who decline genetic testing. J Clin Oncol. 1998;16:1650-4.

35. Charmaz K. Loss of self: a fundamental form of suffering in the chronically ill. Sociol Health III. 1983;5:168-95.

36. Charmaz K. Struggling for a self: identity levels of the chronically ill. Res Sociol Health Care. 1987;6:283-321.

37. Charmaz K. Good days, bad days: the self in chronic illness and time. New Brunswick: Rutgers University Press; 1991.

38. Metcalfe KA, Liede A, Hoodfar E, Scott A, Foulkes WD, Narod SA. An evaluation of needs of female BRCA1 and BRCA2 carriers undergoing genetic counselling. J Med Genet. 2000;37:866-74.

39. Douglas HA, Hamilton RJ, Grubs RE. The effect of BRCA gene testing on family relationships: a thematic analysis of qualitative interviews. J Genet Couns. 2009;18:418-35.

40. Kenen R, Ardern-Jones A, Eeles R. "Social separation" among women under 40 years of age diagnosed with breast cancer and carrying a BRCA1 or BRCA2 mutation. J Genet Couns. 2006;15:149-62.

41. Hamilton R. Being young, female, and BRCA positive. Am J Nurs. 2012;112:26-31.

42. den Heijer M, Vos J, Seynaeve C, Vanheusden K, Duivenvoorden HJ, Tilanus-Linthorst M, Menke-Pluymers MB, Tibben A. The impact of social and personal resources on psychological distress in women at risk for hereditary breast cancer. Psycho-oncology. 2012;21:153-60.

43. Hamilton RJ, Williams JK, Bowers BJ, Calzone K. Life trajectories, genetic testing, and risk reduction decisions in 18-39 year old women at risk for hereditary breast and ovarian cancer. J Genet Couns. 2008;18:147-54.

44. Werner-Lin A. Beating the biological clock: the compressed family life cycle of young women with BRCA gene alterations. Soc Work Health Care. 2008;47:416-37.

45. Hamilton RJ, Hurley KE. Conditions and consequences of a BRCA mutation in young, single women of childbearing age. Oncol Nurs Forum. 2010;37:627-34.

46. Miesfeldt S, Jones SM, Cohn WF. Informed consent for BRCA1 and BRCA2 testing: what clinicians should know about process and content. J Am Med Womens Assoc. 2000;55:275-9.

47. Godard B, Hurlimann T, Letendre M, Egalite N. INHERIT BRCAs. Guidelines for disclosing genetic information to family members: from development to use. Fam Cancer. 2006;5:103-16.

48. Menikoff J. To tell or not to tell: mandating disclosure of genetic testing results. Am J Bioeth. 2001;1:19-20.

49. Plass AM, Baars MJ, Cornel MC, Julian-Reynier C, Nippert I, Harris H, Kristoffersson U, Schmidtke J, Anionwu EN, Benjamin C, Challen K, Harris R, ten Kate LP. Testing the children: do non-genetic health care providers differ in their decision to advise 
genetic presymptomatic testing on minors? A cross-sectional study in five countries in the European Union. Genet Test Mol Biomark. 2009;13:367-76.

50. Multhaupt-Buell TJ, Lovell A, Mills L, Stanford KE, Hopkin RJ. Genetic service providers' practices and attitudes regarding adolescent genetic testing for carrier status. Genet Med. 2007;9:101-7.

51. Werner-Lin A. Formal and informal support needs of young women with BRCA mutations. J Psychosoc Oncol. 2008;26: 111-33.

52. Hamilton RJ, Bowers BJ. The theory of genetic vulnerability: a roy model exemplar. Nurs Sci Q. 2007;20:254-65.

53. Klitzman RL, Sweeney MM. "In sickness and in health"? Disclosures of genetic risks in dating. J Genet Couns. 2011;20:98-112.

54. Kelly M. Self, identity and radical surgery. Sociol Health III. 1992;14:390-415.

55. Williams SJ, Calnan M. Perspectives on prevention: the views of general practitioners. Sociol Health III. 1994;16:372-93.

56. Rose N. Medicine, history, and the present. In: Jones C, Porter R, editors. Reassessing foucault: power, medicine, and the body. London: Routledge; 1994. p. 48-72.

57. d'Agincourt-Canning L. A gift or a yoke? Women's and men's responses to genetic risk information from BRCA1 and BRCA2 testing. Clin Genet. 2006;70:462-72.

58. Cancer Previvors. FORCE: Facing Our Risk of Cancer Empowered, Inc. https://www.facingourrisk.org/info_research/previvorssurvivors/cancer-previvors/index.php. Accessed 24 April 2014.

59. Arnett JJ. Are college students adults? Their conceptions of the transitions to adulthood. J Adult Dev. 1994;1:213-24.

60. Arnett JJ. Young people's conceptions of the transitions to adulthood. Youth Soc. 1997;29:3-23.

61. Arnett JJ. Learning to stand alone: the contemporary American transition to adulthood in cultural and historical context. Hum Dev. 1998;41:295-315.

62. Arnett JJ. Emerging adulthood: a theory of development from the late teens through the twenties. Am Psychol. 2000;55:469-80.
63. Perry WG. Forms of intellectual and ethical development in the college years. New York: Holt, Rinehart \& Winston; 1970/1999.

64. Schlegel A, Barry H III. Adolescence: an anthropological inquiry. New York: Free Press; 1991.

65. Klitzman R. "Am I my genes?": questions of identity among individuals confronting genetic disease. Genet Med. 2009;11: 880-9.

66. Berg JW, Appelbaum PS, Lidz CW, Parker LS. Informed consent: legal theory and clinical practice. 2nd ed. Fair Lawn: Oxford University Press; 2001.

67. ACMG Board of Directors. Points to consider in the clinical application of genomic sequencing. Genet Med. 2012;14:759-61.

68. Burke W, Antommaria AHM, Bennett R, Botkin J, Clayton EW, Henderson GE, Holm IA, Jarvik GP, Khoury MJ, Knoppers BM, Press NA, Ross LF, Rothstein MA, Saal H, Uhlmann WR, Wilfond B, Wolf SM, Zimmern R. Recommendations for returning genomic incidental findings? We need to talk! Genet Med. 2013;15:854-9.

69. Green RC, Berg JS, Berry GT, Biesecker LG, Dimmock DP, Evans JP, Grody WW, Hegde MR, Kalia S, Korf BR, Krantz I, McGuire AL, Miller DT, Murray MF, Nussbaum RL, Plon SE, Rehm HL, Jacob HJ. Exploring concordance and discordance for return of incidental findings from clinical sequencing. Genet Med. 2012;14:405-10.

70. Parker LS. The future of incidental findings: should they be viewed as benefits? J Law Med Ethics. 2008;36(341-51):213.

71. Green RC, Berg JS, Grody WW, Kalia SS, Korf BR, Martin CL, McGuire AL, Nussbaum RL, O’Daniel JM, Ormond KE, Rehm HL, Watson MS, Williams MS, Biesecker LG. ACMG recommendations for reporting of incidental findings in clinical exome and genome sequencing. Genet Med. 2013;15:565-74.

72. American College of Medical Genetics and Genomics. Incidental findings in clinical genomics: a clarification. Genet Med. 2013;15:664-6. 